\section{Getting personal for a purpose}

\author{
Stephen Hancocks OBE \\ Editor-in-Chief
}

Send your comments to the

Editor-in-Chief,

British Dental Journal

64 Wimpole Street,

London

W1G 8YS

Emailbdj@bda.org
It seems curious, on reflection, that there was a time when the notion of dentists screening for oral cancer was not regarded as particularly routine. The advent of soft tissue mouth maps to guide and record such examinations was greeted, as I recall, with some suspicion and a slight bewilderment as to whether or not such a procedure was really called for. These years on and with the very valuable awareness raising for professionals and public alike that is provided by charities operating in the field of oral cancer, November being designated Mouth Cancer Action Month, the importance of the condition is now attaining its rightful place in the hierarchy of dental practice.

Different authorities quote differing figures for incidence and mortality depending on the definitions of the pathology, some including oral lesions only while others additionally account for those in the oro-pharyngeal region. However, by whatever means the figures are recorded and reported the trend is, sadly, on the same upward path with a particularly marked increase in younger age groups. The reasons for this are not yet entirely clear but may revolve around the risk factors of alcohol consumption and the human papilloma virus (HPV) as detailed further in the Opinion paper in this issue. ${ }^{1}$ What is clear is that further research is required, that catching the condition at as early a stage as possible is crucial if treatment is to be effective and that preventive advice and awareness is also key in avoiding or defeating what is a devastating life event.

Discussion on the possible role of alcohol-containing mouthwashes in the aetiology of oral cancer is contained in both the Opinion paper and one of the Research papers in this issue and online. ${ }^{1,2}$ Important as any possible cause of a condition is, the recent focus and controversy over this possible factor may be in danger of over-shadowing those of far greater significance, namely social alcohol use and abuse, and tobacco use. A parallel may be drawn between this and focussing on the relative value of the use of mouthwash and tooth brushing in plaque control: both have value but the effect is far greater in the case of the latter.

\section{ENGAGING WITH PERSONAL HABITS}

What I think the focus on oral cancer does highlight for us as clinicians is the continuing shift towards engaging our patients in discussions on personal habits and on the relation between oral health and general health. In the same way that I alluded above to a time when screening was thought to be on the periphery of our role, so too was the idea that we should discuss matters such as smoking cessation. The argument put forward consisted of the claim that it was not our place to review such individual decisions as they were too personal and therefore outside our remit. This often seemed strange reasoning given that we were content to talk about diet and oral hygiene habits as falling within our realm of responsibility, and it could be equally argued that both of these touch on the very personal as well. It may be that the objection was based on two other factors which frequently underlie barriers to the provision of smoking cessation advice: lack of funding to undertake it and insecurity about delivering it due to a deficiency or absence of training. If the will exists, each of these can be solved. With increasing patient engagement in healthy living the possibility of providing such services on a private basis is much greater and with this overall interest, training courses and other materials are also more readily available.

It may well be that this will lead to greater involvement of dentists and dental professionals in wider healthcare for patients. It has been suggested that our future role will be inclined towards that of oral physicians rather than surgeons and with falling caries rates in particular, the amount of cutting required is likely to decline dramatically. In particular I wonder whether or not preventive advice on alcohol consumption will become a greater part of engagement with patients than hitherto, in exactly the way that tobacco has become a consideration. The problems caused by alcohol use have increased substantially in the UK in recent years and the reluctance to accept it as a drug but rather as a socially acceptable habit masks our ability, or willingness, to properly acknowledge its truly enormous effects on our social fabric as well as on an individual's health. Past reticence may well turn to future imperative especially if the upsurge in oral cancer in young people is traced to an increased consumption at an early age.

Meanwhile, with deference to Mouth Cancer Action Month and the thousands of people affected each year by this shattering condition, we must all redouble our efforts to help prevent it wherever possible and to detect it as early as we possibly can.

1. Warnakulasuriya S. Causes of oral cancer - an appraisal of controversies. BrDent J 2009; 207: 471-475.

2. Werner $\mathrm{CW}$ de A, Seymour R A. Are alcohol containing mouthwashes safe? Br Dent J 2009; 207: E19 